
Berelson, B. 1960. Graduate Education in the United States. New York:
McGraw-Hill.

"Best Places to be for a Ph.D." 1983. Changing Times (November):64-67.

Survey of 100 . 1975. A Preliminary Report on a Reputational Standing Conduted in Ph.D. Producing Departments in the United States Caplow, T. and Spring 1975. Unpublished report circulated in 1975.

Anchor-Doubleday. McGee. 1965. The Academic Marketplace. New York:

Cartter, A.M.1966. An Assessment of Quality in Graduate Education. Washington, D.C.: American Council on Education.

Gross, G.R. 1970. "The Organization Set: A Study of Sociology Departments." American Sociologist 5:25-29. Helmer, J. 1974. The Deadly Simple Mechanics of Society. New York: The
Seabury Press.

Jones, Lyle V. and Porter E. Coggeshall. 1982. An Assessment of ResearchDoctorate Programs in the United States: Social and Behavioral Sciences. Washington, D.C.: National Academy Press.

Ladd, Everett C. and Seymour M. Lipset. 1979. "Faculty Rankings of University Departments." Chronicle of Higher Education. January 15.

Marx, Karl and Frederick Engels. 1967. The German Ideology Parts I and II, edited by R. Paschal. New York: International Publishers.

Economics. and Larry R. Cross. 1982. Guide to Graduate Study in Economics and Agricultural Economics. Boulder, Colorado: Economics

Roose, Kenneth D. and Charles J. Anderson. 1970. A Rating of Graduate Programs. Washington, D.C.: American Council on Education. Schichor, D. 1970. "Prestige of Sociology Departments and the Placing of New
Ph.D.'s." American Sociologist 5:157-160.

\section{FEMALE GANG DELINQUENCY: \\ A SEARCH FOR "ACCEPTABLY DEVIANT BEHAVIOR"}

\section{William J. Swart}

The University of Kansas

Mid-American Roview of Sociology, 1991, Vol. XV, No. 1:43-52

This paper explores the forms of female gang delinquency through an analysis of ambiguous deviance noms operating within the gang structure. Caught within competing behavioral norms, female gang members are forced to "fine tune" their deviant behavior in order to make it "acceptable" to their unique position as females within a delinquent gang. The resulting behavior is a "typical" form of female delinquency which is deviant enough for gang membership but not so deviant as to be seen as a contradiction to female character expectations. The explanatory framework and coinciding specific forms of "acceptable deviance" are examined in light of the sexual promiscuity, drug use, aggressive or violent behavior, and motherhood of female gang members.

The historic commitment to the assumption that deviance is a typically male phenomenon has had a great impact on the theoretical and empirical framework from which the gang phenomenon has been studied. In general, Carol Smart (1976) has indicated that a "sexist ideology" operates within both contemporary and historic criminological theory; thus our understanding of female deviance has been biased by current gender stereotypes. Because of these assumptions about gender-typed behavior, little research exists on the role females (and more specifically, female deviant behaviors) play within gang networks. The research that does exist primarily focuses on the female role in relation to males, where males play the dominantly deviant role, and females act to support male deviance (i.e. transporting weapons, providing alibis, acting as spies and lures, and providing sex for male gang members (Campbell 1984, p. 14).

While such research is informative, it does little to aid our understanding of the dynamics motivating female gang members toward certain types of bchavior. Why does female gang delinquency tend to be "male supportive" and of "lower intensity" than male gang delinquency? Does the gang structure have any impact on the female member's chosen forms of deviance? While current descriptions of "typical female gang delinquency" can be partly explored through Smart's theoretical sexist ideology and the related "self fulfilling prophesy" in the arrest behavior of police, there seems to be still another dynamic involved--a dynamic which is operating on the level of the individual female gang member's perception and rooted in the gang structure itself. 
In her paper on male and female gang members, Giordano (1978) discusses the relevance of peer networks to the role played by the female gang member. She concludes that "for both the white and black sub-samples, there was a significant association between group affiliation and self-reported delinquency." Contrary to much research, she also concludes that "the pattern appears to be more complex than the notion that the boyfriend simply uses the female in an 'accomplice' or other passive role while he commits the crime" $(1978$, p. 132).

The purpose of this paper is to examine this "complex pattern" from which female gang delinquency occurs. By reviewing the analysis and conclusions of Campbell (1984, 1987), Giordano (1978), Horowitz (1986), Rice (1963), and Smith (1978), this paper will examine the role the gang plays as a "peer" network and what effect this network has on the type and extent of the female gang members' deviant behavior. Here, "female gang member" refers to a group of women who act as an auxiliary counterpart to a male gang. By taking this network into effect (as opposed to the examination of female gangs independent of and unaffiliated with male gangs), this paper will provide an alternative explanatory framework for understanding the behavior of female gang members.

In his work on gender stigma and social control, Schur (1984) identifies an attitude of ambivalence toward women present within modern social structures. A major part of Schur's work operates under the assumption that "female" is a devalued status in current society. Thus, in complex modern societies, "Extensive role-overlap and role conflict imply that often [female] behavior may be both 'conformist' and 'deviant' at the same time--depending on which set of expectations governs the evaluation." When females attempt to break out of "traditional" female behavior, "liberated" women are labeled deviant because they do not measure up to social expectations; however, acting in "traditional" female behavior patterns is itself deviant because "male" has become the expected social norm. In this event, female behavior is often "deviant either way;" whether acting in a traditional or liberated manner, female behavior "reflects the uniquely high degree of 'structural ambivalence' that has dominated thinking about women's roles. It reflects as well the generic stigma...ascribed merely on the basis of being a woman..." $(1984, \mathrm{p}$. 52).

Inferring from the conclusions presented by the gang literature, it seems that an attitude of ambivalence toward women similar to that which Schur indicates is also evident among gang members. This is especially evident in the research Anne Campbell $(1984,1987)$ presents on female gang members' perception and self definition. In her work, Campbell (1984) identifies two factors that help interpret the role of girls in gangs: their class-value orientation (their desire and ability to be upwardly mobile in terms of their life-style), and the role that females take toward males. The typified roles that follow from these two factors can be summarized in the following table:
CLASS-VALUE

ORIENTATION

\begin{tabular}{|c|c|c|c|}
\hline & & Good Girls & Bad Girls \\
\hline TOWARD & Complementary & $\begin{array}{l}\text { Good } \\
\text { Wives }\end{array}$ & $\begin{array}{c}\text { Sex } \\
\text { objects }\end{array}$ \\
\hline$E N$ & similar & $\begin{array}{l}\text { Independent } \\
\text { Women }\end{array}$ & Tomboys \\
\hline
\end{tabular}

In her discussion of these typified roles, Campbell alludes to the structural ambivalence mentioned above:

These types of roles tend to suggest a no-win situation for gang girls. As Sex Objects, they are cheap women rejected by other girls, parents, social workers, and ironically often by the boys themselves. As Tomboys, they are resented by boys and ridiculed by family and friends who wait patiently for them to "grow out of it." Among lower-class women, the Independent Woman, as often as not, raises her children in an all-female household. In doing so, she becomes the target of government, academic, and media concern by those who accuse her of rearing a new cycle of delinquents or, if she works, of ousting the male from the labor force by taking low wages.... Clearly the most socially acceptable role is that of Good Wife. Yet even here the Woman is often characterized as the fun-spoiling petty bourgeoisie who takes the high-spirited male away from his gang friends to a future of shopping expeditions and diaper changing $(1984$, p. 9$)$.

The "deviant either way" status of female gang members is also presented by Rice in his study of the Persian Queens.

He [Rice] noted that there is nothing that females can do to achicve power or prestige in the gang world. If they fight, male gang members consider them to be deviant, and if they play a more seductive, traditionally feminine role, they are disregarded except for sexual purposes (Bowker and Klein 1983, p. 740).

The ambivalent attitude and "deviant either way" phenomena operating within the gang plays a unique role in the deviancy of female gang members. On the one hand, the female gang member's behavior must be "deviant" to 


\section{Mid-American Review of Sociology}

those outside of the gang in order to ensure her place within the gang itself. On the other, it must not be too deviant so as to be viewed negatively by other gang members (both male and female) whose perception is affected by the ambivalent attitude previously discussed. Struggling to find an "acceptable" type and measure of deviance, female gang members expcrience a state of "normative ambiguity" analogous to that discussed by Horowitz (1986) in her book Honor and the American Dream.

In her discussion of the culture and identity of a Chicano community, Horowitz identifies a two-dimensional view of culture where behavior is constrained through the normative ambiguity of two competing codes found within the social structure of the Chicano community itself. The Expressive Code, pertaining to the maintenance of personal and family honor, is deeply rooted in the Latin culture and constantly open to challenge. The Instrumental Code, on the other hand, stems from the Protestant work ethic and includes the pursuit of the American Dream through hard work and education. The tension between these two codes causes conflict because "behavior that is highly valued in one setting may be denigrated in another," while different settings occur within a single social space. Thus, the tension between different settings occur with the codes "is revealed through various cultural dilemmas, which in turn reflect the disparities between economic and social aspirations and the realities of everyday life in the inner city" (1986, p. 26-27).

The normative ambiguity resulting from the ambivalent attitude of the gang toward women means that female gang members must "fine tune" their gang toward behavior in much the same way as the subjects of Horowitz' study deviant behavior in muvior to stay within the two conflicting codes. As part of a delinquent subculture, there are expectations of female gang members' a delinquent subculture, thative conflict with the larger society; while at the behavior that are in normative conflict with the larger society; while at the whole is required. The result is that female gang members must operate whole is required. The ren contradictory normative contexts, in order to find a level of behavior which is "acceptably deviant" to the other gang members.

The remainder of this paper will focus on the sexual promiscuity, drug use, Thesive or violent behavior, and motherhood of female gang members in an attempt to present the explanatory framework previously discussed.

\section{SEXUAL PROMISCUITY}

There can be little doubt that the common understanding of female There can be little doubt that in sexually promiscuous behavior. While celinquency predomitis show that young women are most likely to be arrested for current statistics show (sexual promiscuity, running away, etc.,) it appears that within the gang structure the promiscuity of female gang members comes under careful scrutiny by both male and female participants. This is not to deny that part of the female gang members' relation to the male gang
Female Gang Delinquency

members is sexual. One only needs to read a small sample of the available literature to understand that sexual activity on the part of both male and female gang members is one major source of deviance. However, an explanation of female gang delinquency relying solely on rampant sexual promiscuity simply isn't an adequate explanation.

The female gang member's relationship to males is important for several reasons, not the least of which is protection from the threats of the inner city. Many have indicated that the existence of the female gang itself relies upon it's affiliation to a male counterpart. For this reason, many female gangs will actually take on gendered versions of the male gang name. Two of the female gangs directly studied by Campbell (1984), the Sandman Ladies and the Sex Girls, were correlates to already existing male gangs (the Sandman and the Sex Boys or Essex Boys), and Campbell indicates others in the beginning chapters of her book.

Thus, while the female gang's relation to a male counterpart is important to the existence of the female gang, the relationship is not simply sexual. In reality, while some sexual promiscuity is "normal" gang behavior, "whores" and "loose" girls are negatively sanctioned by both male and female gang participants. As Campbell (1987) indicates, "The social talk of delinquent girls generally shows that they not only reject sexual activity outside the context of a steady relationship but even reject friendships with 'loose' girls whose reputation might contaminate them by association" (pp. 451-52). In this case, rampant sexual activity among gang girls was sanctioned by other female members who wouldn't associate with them. "New girls in the group who, unaware of the prevailing norms, slept around with a variety of men were called to account for their behavior at meetings and instructed that serial monogamy was required" (p. 461).

Campbell indicates two reasons for this emphasis on serial monogamy. First, this emphasis is in part motivated by the girls' own interest in protecting their current relationships with their boyfriends. Fights among female gang members are often the result of a breach in this gang standard. Interestingly enough, the second reason revolves around a struggle for male respect, which the female gang members' felt-would be lost if they participated in unselective sexual activity.

These dynamics cause female gang members to find themselves in an ambiguous situation between two conflicting norms (i.e. sexual purity and rampant sexual promiscuity). Sexual purity carries connotations of Campbell's "Good Girls;" a connotation most likely not present among female gang participants. However, while a certain amount of sexual behavior is expected of female gang members as gang activity, extreme sexual promiscuity is deemed unacceptable. "Whores" are strictly sanctioned by female gang members and disregarded by their female peers if they fail to change their "loose" behavior. The resulting serial monogamy of female gang members, then, can be seen as the consequence of an attempt to act normatively in a 
uniquely ambiguous situation. Caught between the extremes of sexual purity and excessive promiscuity, monogamous relationships serve as an "acceptably deviant" outcome for female gang members.

\section{DRUG USE}

Similar to sexual promiscuity, the use and abuse of illegal drugs is a typical form of gang delinquency. Consequently, both male and female gang members who participate in drug use are often seen as drug addicts and abusers in the eyes of the local community and police. However, inferring from the data, it is interesting to note that while female gang members are involved in the use of drugs, their involvement usually includes only the use of light drugs and is less likely to involve use and abuse of heavy drugs such as LSD, PCP, and heroin. In Campbell's (1987) work, the place of marijuana in the lives of gang members (both female and male) was "as uncontroversial as that of alcohol" (p. 458). However, the female members made a distinction between use and abuse, as well as hard and soft "types" of drugs.

When they [the gang girls] talked about drug abuse, they drew a clear line between recreational use and addiction.... The girls took pains to distance themselves from any such involvement. Heroin users were seen as undependable, capricious, and irresponsible, and they were generally not welcome within the gang (Campbell 1987, p. 458).

Drug abusers were perceived by the women as unreliable, inconsistent, and committed only to themselves and their addiction. For this reason, drug addicts and abusers were usually not welcome within the female gang, and those in the gang who developed drug problems were encouraged to seek help in kicking their addiction. In addition, while men who were successful in illegal activities were sought after by females, the female members were leery of becoming involved in relationships with male drug abusers. "Males who had successful hustles were a prized commodity and addicted males were considered a liability since-any income they might cbtain was spent on heroin.". (Campbell 1987, p. 457)

The specific use of drugs for only recreational purposes can be seen as another indicator of the female gang member's struggle to find a level of "acceptably deviant" behavior. While surrounded by a positive outlook on recreational drug use and an abundant supply of drugs, the female gang member was at the same time discouraged from drug abuse and leery of others who might have this problem. This served to define the two extremes of drug use, abstinence and addiction, from which the women were to discover an "acceptable" midpoint.

\section{AGGRESSIVE BEHAVIOR/VIOLENCE}

Current studies of female gang delinquency focus on the extent of violent female behavior in terms of its relation to male views of traditional female roles. Campbell (1984) indicates:

"Fighters" and "drinkers" both fall into the "bad girl" category, although in different ways. A "bad girl" is one who cheapens herself by abusing her sexuality, but "bad" is also applied to girls who behave in breach of their complementary feminine role $(1984$, p. 31$)$.

Thus, while aggressive behavior serves as a means for positive status among male gang members, it does the opposite for female gang members. Female gang members who are excessively violent are seen as "breaching" their feminine role, and are not usually welcome in the gang. "If a girl fights as well as a boy--boys don't like her, and in no walk of life is a girl whom boys don't like an object of admiration or envy to other girls" (Rice 1963, p. 135).

At the same time, however, a certain amount of aggression is expected of female gang members. Often one of the initiation rites for female gang members involves a test of their toughness and ability to fight. The "jumping in" process consists of the candidate subjecting (and defending, if possible) herself to a short-lived fight with the rest of the gang members or with one especially tough female member. If the candidate proves capable of defending herself and protecting gang turf, then she is allowed to enter the gang (Campbell 1984, p. 25).

These two opposite forces again serve to place the gang girls into an ambiguous situation. While displaying a certain amount of aggressive behavior is necessary for female gang members' acceptance into and participation with the gang, excessive violence is deemed a breech of appropriate female roles and is sanctioned. "Acceptably deviant" behavior is found somewhere in between these two extremes; ordinarily in female aggression against other females. This aggression usually takes the form of "cat fighting" ôver përsonal integrity or jealousy over relationships with males. At times the women might become involved in inter-gang conflict, but again, during these instances their violence is limited to fighting with members of the female auxiliary of another gang.

\section{MOTHERHOOD}

Motherhood seems to play a unique role in constraining the identity and behavior of the female gang member. While pregnancy and motherhood does not necessarily mean that female gang members have to break away from the gang, it does mean that they have to constrain their deviant behavior to the 
extent that it allows them to be seen as "good mothers." As Horowitz indicates in her study of Hispanic gangs:

the Hispanic girl is likely to be deeply concerned about her identity as a good mother. To avoid any imputation of irresponsibility as a mother, she must make every effort to demonstrate her dedication to the welfare of her child. A good deal of gossip among gang members centered on girls who failed to take adequate care of their children. Motherhood did not require abandonment of the gang, but it did entail making satisfactory arrangements for the child. Girls who brought their children with them to the corner to hang out were considered irresponsible. The appropriate course of action was to leave the child with the grandmother for the night. After an all-night party, the girls would conscientiously return home in the early hours to get their children ready for school (Campbell 1987, p. 460).

In this way, the status of female gang members as mothers again places their behavior under the constraints of the gang network. Although motherhood does not require the female members to desert the gang, it does require that they amend their deviant behavior in order to adapt to their new status as mothers. Thus, motherhood brings yet another situation of normative ambiguity to the female gang member. If she remains in the gang, she is expected to participate in gang activities. However, with the onset of motherhood, her participation in these activities now comes under the unique scrutiny of the gang structure, and she is once again forced to struggle to find an "acceptable" level of deviant behavior.

The issue of abortion adds another problematic dimension to the situation of female gang mothers. Often males view fathering a child as an indication of their masculinity. Females, on the other hand, appreciate their independence and are often wary of being "controlled" by men through pregnancy. While abortion is a viable solution to this over dependence on males, excessive use of abortion carries connotations within the gang network of poor mothering.. .

Wholehearted support [for abortion] might be construed as callous disregard for human life and place [the mothers] in jeopardy of being seen as "bad mothers." On the other hand, too many children could lead to a male-dependent life-style and suggest that they were vulnerable to being "conned" by men (Campbell 1987, p. 460).

Constrained by the perception of being either a bad mother or exploited by men, female gang mothers are forced to adjust their behavior between these two extremes. Thus, "abortion was accepted as legitimate after the first or second child but was generally condemned in a first pregnancy" (Campbell
1987, p. 460). Here again the struggle within the ambiguity of competing norms of motherhood shows how opposing forces operating within the gang structure constrain and delimit appropriate female behavior.

\section{CONCLUSION}

This paper attempts to show that an ambivalent attitude, similar to that which Schur (1984) notes, is operating toward women within society as a whole and is also operating toward women within gang networks. I suggest that this ambivalent attitude plays a large role in defining what this paper refers to as "acceptable deviant behavior" for female gang participants. Campbell (1987) suggests something similar when she says that female gang members "arrive at a female gang identity by default rather than by affirmation":

By "backing away" from one aspect of an assigned role, she may run the risk of being cast into another unacceptable role from which she must also extricate herself. For example, in rejecting women's passivity toward men, a girl may endorse her support for abortion. However, in doing so, she risks being seen as cheap or as a bad mother. ... As long as her self presentation depends upon rejecting an interlocking set of actions or qualities, she is likely to find herself escaping from one rejected identity but risking entry into another (p. 452).

The model presented seeks to extend Campbell's understanding by saying that female gang members find themselves amidst the paradox of being "deviant either way." In an attempt to participate in behavior which is deviant to the social status quo, but not excessively deviant in relation to prescribed female gang roles, female gang members find themselves facing an ambiguous situation between competing behavioral norms. As this paper has argued, "typical" female gang delinquency may be more fully understood as it relates to female gang members struggle from ambiguity to "acceptably deviant" patterns of behavior.

Before concluding this paper, it is important to note that in the previous examples given, the ambivalent attitude toward female gang members described was not simply a product of male gang members' dominance, but actually took into account the perception of both the males and females involved. Often normative constraints relied mainly on the perception of other females in the gang. Other studies support this. As Bowker and Klein (1983) indicate, "Relationships with girlfriends are more important in determining gang membership and seriousness of delinquency than any of the other variables discussed in this article" (p. 749). Campbell (1984) concludes the introduction to her book by saying "A girl's status depends to a larger (or perhaps simply more evident and self-admitted) extent on her female peers. 


\section{Mid-American Review of Sociology}

They show their evaluation of her through their own rites and meetings" ( $p$. 32).

This differs from Schur's notion of the source of the structural ambivalence present within society. While Schur implies that the devaluation of women propagates from and is supported by the behavior and perception of men, the literature cited indicates that female gang members are influenced more by the constraints of their female peers than by the perceptions of male gang members. Contrary to the literature, one could argue that because female gangs are most often auxiliary components to male gangs, female gang members are more dependant upon their male counterparts to define gender-related norms than are females in the society at large, where independent female associations are more likely to occur. Nevertheless, what seems necessary is to approach female gang delinquency and the normative structure of the gang as it relates to both male and female peer influences, recognizing that both are important determinants of delinquent behavior. This paper has been an attempt to begin such a process.

\section{REFERENCES}

Bowker, Lee H. and Malcom W. Klein. 1983. "The Etiology of Female Juvenile Delinquency and Gang Membership: A Test of Psychological and Social Structural Explanations." Adolescence 18:738-51

Campbell, Anne. 1987. "Self Definition by Rejection: The Case of Gang Girls." Social Problems 34:451-65

1984. The Girls in the Gang. New York, NY: Basil Blackwell Inc

Giordano, Peggy C. 1978. "Girls, Guys and Gangs: The Changing Social Context of Female Delinquency." The Joumal of Criminal Law Criminology 69:126-32.

Horowitz, Ruth. 1986. Honor and the American Dream: Culture and Identity in a Chicano Community. New Brunswick, NJ: Rutgers University Press.

Rice, R. 1963. "A Reporter at Large: The Persian Queens." New Yorker October 19, 39:153.

Schur, Edwin M.1984. Labeling Women Deviant: Gender, Stigma and Social Control. New York, NY: Random House Inc.

Smart, Carol. 1976. Women, Crime, and Criminology: A Feminist Critique. Boston: Routledge and Kegan Paul.

Smith, Lesley S. 1978. "Sexist Assumptions and Female Delinquency: An Empirical Investigation." In Women, Sexuality and Social Control, edited by Carol Smart and Bary Smart. London: Routledge \& Kegan Paul.

\section{GENDER AND EVALUATION IN FINE ART*}

Tracy X. Karncr

The University of Kansas

Mid-American Roview of Sociology, 1991, Vol. XV, No. 1:53-69

The significance of gender and its potential as a stigmatic social label in the field of ant is investigated. As ant objectifies both a society's ideals and biases, the recognition and appreciation of ant can be seen as a pivotal point from which to study social values. Gender, having been previously identified as a stigmatic label in formalized careers, is hypothesized to account for the lack of recognized ant works by women. Especially as the realm of an has no formalized criteria for evaluating competence. The supposed existence of an aesthetic difference between the ant works of men and women is also explored.

\section{INTRODUCTION}

"At last, a woman on paper!"

"Why they're genuinely fine things--you say a woman did these-She's an unusual woman--She's broad minded, she's bigger than--most women, but she's got the sensitive emotion--I'd known she was a woman, O look at that line...." (Alfred Stieglitz is rumored to have exclaimed upon discovering the work of Georgia O'Keeffe in Castro 1985, p. 31).

All social estimations of good versus poor are by definition subjective; artistic demarcation is no exception. Such evaluation is, however, a very broad and complex process. This project focuses exclusively on the perception and presumption of sex and gender differences in the field of fine art. Whether an artist's gender influences the production of her/his artwork or merely the reception of it, has long been debated. Are decisions of recognition based.en. an artist's talent (or lack of talent) or on an "expert's" subjective vicw of something other than the work--the sex of the artist? The orientation of this research is gender and its potential as a stigmatic social label for women in
the field of art.

"I wish to acknowledge the assistance of James Aho, Paul Zelus, and Miles Friend for their comments and support.

This project was in part funded by an Idaho State University Graduate Student Research Grant, Fall 1987. 